\title{
Eficácia versus viabilidade econômica do controle químico e genético da ferrugem da folha em trigo
}

\author{
Efficacy versus economic viability of the chemical and genetic control for leaf rust on wheat
}

\author{
Marlon Assunção ${ }^{I}$ Adalci Leite Torres ${ }^{I I}$
}

\section{RESUMO}

O objetivo deste trabalho foi avaliar a eficiência de controle versus viabilidade econômica do controle químico e genético da ferrugem da folha em trigo. Sob delineamento de blocos casualizados em arranjo fatorial triplo, com três repetições, foram utilizadas duas cultivares ('BRS 220' e 'Vanguarda'); duas épocas de aplicação (preventiva e curativa); e dois e uma mistura de ingredientes ativos (tebuconazole, trifloxistrobina, tebuconazole + trifloxystrobina) e testemunha. Os resultados mostraram que o uso de cultivar resistente foi o mais eficiente, com aceitável retorno econômico e para a cultivar moderadamente suscetível foi indispensável à utilização do controle químico, dando preferência ao uso de mistura de ingredientes ativos pertencentes aos grupos dos triazóis e estrobilurinas, em aplicações preventivas.

Palavras-chave: retorno econômico, controle químico, Puccinia triticina Erikss.

\section{ABSTRACT}

The objective was to evaluate the efficiency and the economic viability of the fungicides application, under a randomized block design in three factorial arrangement with three replicates, were utilized two cultivars ('BRS 220'and 'Vanguarda'); two timing of application (preventive and curative), and three active ingredients (tebuconazole, trifloxystrobin, tebuconazole + trifloxystrobin) and control. The results showed that the use of resistant cultivars is the most efficient with considerable economic return for both times of application, for moderately susceptible cultivars is essential the use of chemical control giving preference to the use of mixture of active ingredients of the triazoles and strobilurins group, in preventive applications.

Key words: economic return, chemical control, Pucciniatriticina Erikss.

\section{INTRODUÇÃO}

A discussão atual entre triticultores com relação ao alto custo de implantação e do risco da redução de produtividade da cultura de trigo tem aumentado a cada ano, redução esta, podendo estar relacionada com doenças foliares, tais como, a Ferrugem da folha (Puccinia triticina Erikss.) (BOHATCHUK et al., 2008).

Reduções de produtividade dependem do estádio de desenvolvimento da cultura em que a doença ocorre, também da severidade, que é função da suscetibilidade da cultivar, da virulência da raça fisiológica do patógeno em questão e das condições ambientais, as quais na região sul são favoráveis para o aumento da intensidade da doença (REIS \& CASA, 2005; CAIERÃO et al., 2001).

As reduções no rendimento relacionadas à ferrugem da folha podem alcançar até $80 \%$ na cultivar suscetível 'BR 34', (PICCINI \& FERNANDES, 1995). O emprego de cultivares resistentes é uma das práticas de manejo da ferrugem da folha. A resistência de cultivares de trigo à ferrugem da folha pode ser conferida por atuação simultânea de genes a diferentes raças do patógeno, conhecida como resistência horizontal (resistência poligênica ou quantitativa), ou pela atuação de um único par de gene para uma determinada raça do patógeno, resistência vertical (resistência monogênica ou qualitativa)(CHAVES et al., 2004). A variabilidade genética da população

IPrograma de Pós-graduação em Agronomia, Universidade Estadual de Ponta Grossa (UEPG), Avenida Carlos Cavalcanti, 84030-900, Ponta Grossa, PR, Brasil. E-mail: marlonass@yahoo.com. Autor para correspondência.

"Departamento de Fitossanidade, UEPG, Ponta Grossa, PR, Brasil.

Recebido 16.06.11 Aprovado 23.06.12 Devolvido pelo autor 14.05.13 
de $\boldsymbol{P}$. triticina Erikss é constante, e programas de melhoramento devem estar ligados a estudos dessa variablidade visando à estabilidade da resistência de cultivares (FELICIO et al., 2008)

O emprego de fungicidas é uma prática de manejo altamente eficiente, rápido e emergencial para o controle dessa doença (DALLAGNOL et al., 2006; PICININI \& FERNANDES, 2003). Contudo, critérios devem ser estabelecidos para que o controle justifique a execução da aplicação (BARROS et al., 2006). Aplicações baseadas em Limiar de Ação (LA) é uma alternativa para estabelecer o momento adequado para a execução das aplicações, justificando o uso destas.

Portanto, avaliar a eficiência e a viabilidade econômica do controle químico e genético da ferrugem da folha para a região dos Campos Gerais - Paraná -, em duas cultivares de trigo, com níveis de resistência diferenciados, foram os objetivos do presente trabalho.

\section{MATERIAL E MÉTODOS}

O experimento foi instalado na Fazenda do Centro de Ensino Superior dos Campos Gerais, em um Latossolo vermelho distrófico, na safra agrícola de 2008. A densidade de semeadura foi aproximadamente 350 sementes por $\mathrm{m}^{2}$. Na adubação de base, foram utilizados $420 \mathrm{~kg} \mathrm{ha}^{-1}$ da formulação 8-28-16 (N-P-K).

O controle de plantas daninhas foi efetuado em dessecação antes da semeadura, com herbicida a base de glifosato $\left(480 \mathrm{~g}\right.$ de i.a. ha $\left.\mathrm{h}^{-1}\right)$ e em pós-emergência da cultura (48DAS) com herbicida a base de bentazona ( $720 \mathrm{~g}$ de i.a. ha $\left.{ }^{-1}\right)$. Para controle de pulgões, foi utilizado inseticida a base de dimetoato (252g de i.a. ha-1).

O delineamento utilizado foi o de blocos ao acaso em arranjo fatorial triplo $(2 \times 2 \times 4)$, com três repetições, totalizando 16 tratamentos. O fator " $\mathrm{A}$ " constou de duas cultivares com diferentes níveis de resistência à ferrugem da folha: 'BRS 220' (resistente) e 'Vanguarda' (moderadamente suscetível). No fator "B", as épocas de aplicação: preventivo e curativo; e, em "C", os ingredientes ativos: tebuconazole (120g de i.a. ha $\left.{ }^{-1}\right)$, trifloxistrobina (250g de i.a. ha $\left.{ }^{-1}\right)$, mistura formulada de tebuconazole + trifloxistrobina $\left(120+250\right.$ g de i.a. ha $\left.{ }^{-1}\right)$; e testemunha (ausência de ingrediente ativo).

As pulverizações foram realizadas com auxílio de um pulverizador costal, com pressão constante gerada a $\mathrm{CO}_{2}$, provido de barra de $2 \mathrm{~m}$ de largura e pontas de pulverização espaçadas de $0,5 \mathrm{~m}$.
A pressão de trabalho e o volume de calda utilizado foram de $40 \mathrm{lbs} \mathrm{pol}^{-2}$ e $2001 \mathrm{ha}^{-1}$, respectivamente. Cada unidade experimental constou de $5 \mathrm{~m}$ de comprimento e linhas de semeadura.

A severidade foi obtida antes das aplicações, baseando-se na escala diagramática proposta por LIMACHE (2008). As amostragens constaram de 10 plantas ao acaso em cada unidade experimental, avaliando o terço inferior, médio e superior. Os percentuais de severidade, foram integrados em função dos dias entre as leituras, calculando-se, assim, a área abaixo da curva de progresso da doença (AACPD), pela equação:

$\mathrm{AACPD}=\sum\left\{\left[\left(\mathrm{y}_{\mathrm{i}}+\mathrm{y}_{\mathrm{i}+1}\right) / 2\right] \mathrm{x}\left(\mathrm{t}_{\mathrm{i}+1}-\mathrm{t}_{\mathrm{i}}\right)\right\}$ em que, $y_{i}$ e $y_{i+1}$ - valores de duas leituras consecutivas da severidade; e $t_{i}$ e $t_{i+1}$ - datas das duas leituras.

Realizaram-se três aplicações preventivas, executadas respectivamente nos estádios 6, $10 \mathrm{e}$ 10.51 da escala fenológica de LARGE (1954), considerando o intervalo entre as aplicações o efeito residual de cada fungicida utilizado. As aplicações curativas foram baseadas no limiar de ação (L.A), estabelecido por SILVA et al. (2008), de 10 até $15 \%$ de incidência foliar. O mesmo parâmetro foi adotado como intervalo entre as aplicações.

A colheita foi realizada manualmente, com uma área de amostragem correspondente a $0,25 \mathrm{~m}^{2}$, coletando-se quatro amostras por unidade experimental. A massa média de grãos das amostras na área conhecida foi corrigida para $13 \%$ de umidade e, posteriormente, convertida para produtividade $\left(\mathrm{kg} \mathrm{ha}^{-1}\right)$.

$\mathrm{O}$ retorno econômico foi obtido pela fórmula:

$\mathrm{RE}=(\operatorname{Re} \times \mathrm{Prt})-\{\mathrm{Ct}+[(\mathrm{Cf}+\mathrm{Ca}) \times \mathrm{N}]\}(2)$

Em que: RE: retorno econômico; Re: rendimento em toneladas; Prt: preço da tonelada do produto; Ct: custos totais de implantação; Cf: custo do fungicida por hectare; Ca: custo da aplicação; N: número de aplicações do fungicida. O preço adotado para tonelada do trigo e para os fungicidas utilizados foram aqueles praticados no estado do Paraná no ano referente à execução das aplicações (Tabela 1).

Os dados obtidos foram computados e submetidos à análise de variância (ANOVA) e teste de comparação de médias (Tukey, $\mathrm{P}<0,05$ ), pelo software ESTAT versão 2.0 (UNESP - Jaboticabal).

\section{RESULTADOS E DISCUSSÃO}

A eficiência de controle foi incrementada pelas aplicações preventivas dos ingredientes ativos e a mistura formulada de tebuconazole + trifloxistrobina, independente da época de aplicação, 
Tabela 1 - Descrição de valores para fins de cálculo do custo de implantação da cultura de trigo no estado do Paraná, 2009.

\begin{tabular}{|c|c|c|c|c|c|}
\hline Descrição & Operações & Unid. & Qtde ha ${ }^{-1}$ & $\mathrm{R} \$ \mathrm{Qtde}^{-1}$ & $\mathrm{R} \$ \mathrm{ha}^{-1}$ \\
\hline Tebuconazole & Variável & $\mathrm{L} \mathrm{ha}^{-1}$ & 0,6 & 85,00 & 51,00 \\
\hline Trifloxistrobina & Variável & $\mathrm{L} \mathrm{ha}^{-1}$ & 0,6 & 115,44 & 69,26 \\
\hline Misturaformulada & Variável & $\mathrm{L} \mathrm{ha}^{-1}$ & 0,6 & 75,00 & 45,00 \\
\hline Sementes & 1 & $\mathrm{~kg} \mathrm{ha}^{-1}$ & 130 & 55,00 & 119,17 \\
\hline Adubação de base & 1 & $\mathrm{~kg} \mathrm{ha}^{-1}$ & 420 & $1.997,50$ & 838,95 \\
\hline Glifosato (Herbicida para dessecação) & 1 & $\mathrm{~L} \mathrm{ha}^{-1}$ & 2 & 12,00 & 24,00 \\
\hline Bentazona (Herbicida pós-emergente) & 1 & $\mathrm{~L} \mathrm{ha}^{-1}$ & 1,2 & 29,90 & 35,88 \\
\hline Dimetoato (Inseticida) & 1 & $\mathrm{~L} \mathrm{ha}^{-1}$ & 0,8 & 15,50 & 24,80 \\
\hline Descriçao & \multicolumn{2}{|c|}{ Operações } & ha $h^{-1}$ & $\mathrm{R} \$ \mathrm{~h}^{-1}$ & $\mathrm{R} \$ \mathrm{ha}^{-1}$ \\
\hline Semeadura & \multicolumn{2}{|c|}{1} & 0,73 & 30,00 & 21,90 \\
\hline Pulverização (Herbicidas+Inseticida) & \multicolumn{2}{|c|}{3} & 0,31 & 25,00 & 23,25 \\
\hline Colheita & \multicolumn{2}{|c|}{1} & 0,6 & 50,00 & 30,00 \\
\hline Pulverização de fungicida & \multicolumn{2}{|c|}{ Variável } & 0,31 & 25,00 & 7,75 \\
\hline Descrição & \multicolumn{2}{|c|}{ Unidade } & \multicolumn{2}{|c|}{ Qtde } & $\mathrm{R} \$$ \\
\hline Grão de trigo & \multicolumn{2}{|c|}{ Ton. } & \multicolumn{2}{|c|}{1} & 490,00 \\
\hline
\end{tabular}

foi significativamente superior à aplicação isolada de trifloxistrobina e tebuconazole (Tabela 2), sendo estes valores inversamente proporcionais à AACPD. Esses dados mostram que é possível aumentar a eficiência de controle e redução da AACPD pela atuação simultânea de ingredientes ativos em dois sítios de ação distintos; tebuconazole (demitilação do C14 na biossíntese de ergosterol); e a trifloxistrobina (respiração-ubequinol oxidase no sítio Qo).

A aplicação de triazol isoladamente superou em eficiência de controle a estrobilurina também isolada para ambas as épocas de aplicação, muito embora não se observaram efeitos sobre a produtividade para os respectivos tratamentos.

Em cultivar moderadamente suscetível, as aplicações preventivas proporcionaram valores superiores para eficiência de controle em relação à curativa, com variação de $61 \%$ (coeficiente de variação) (Tabela 3). Embora, na ausência de aplicações curativas, na cultivar resistente em função do L.A, não ser atingido não houve diferença significativa entre as épocas de aplicações para eficiência de controle (Tabela 3). Portanto, pode-se dizer que a expressão genética (resistência à ferrugem da folha) nesta cultivar foi equivalentemente eficiente a três aplicações preventivas, quer sejam elas utilizando tebuconazole, trifloxistrobina ou a mistura formulada.

$\mathrm{Na}$ tabela 4, observa-se que os pontos extremos e significância das médias de eficiência de controle dos ingredientes ativos entre os níveis de resistência são oriundos do efeito associado da expressão dos genes de resistência e o controle químico utilizado.

É evidente a consequência dos níveis de infecção sobre o particionamento de fotoassimilados na cultivar moderadamente suscetível. Esses dados

Tabela 2 - Efeito da interação entre ingredientes ativos e época de aplicação sobre a produtividade (PR \pm IC), eficiência de controle $(E F) e$ área abaixo da curva de progresso da doença (AACPD), Ponta Grossa, PR, 2008.

\begin{tabular}{lllcccc}
\hline \multirow{2}{*}{ Ingredientes ativos } & \multicolumn{1}{c}{ AR $\left(\mathrm{kg} \mathrm{ha}^{-1}\right)$} & EF $(\%)$ & AACPD & PR $\left(\mathrm{kg} \mathrm{ha}^{-1}\right)$ & EF (\%) & AACPD \\
\hline Testemunha & $2366 \pm 1463 \mathrm{cA}$ & $50,0 \mathrm{dA}$ & 323,7 & $2366 \pm 1463 \mathrm{bA}$ & $50,0 \mathrm{dA}$ & 323,7 \\
Tebuconazole & $3805 \pm 318 \mathrm{bA}$ & $90,4 \mathrm{bA}$ & 54,1 & $3003 \pm 1242 \mathrm{aB}$ & $67,9 \mathrm{bB}$ & 150,5 \\
Trifloxistrobina & $3693 \pm 1221 \mathrm{bA}$ & $86,4 \mathrm{cA}$ & 76,5 & $2881 \pm 1838 \mathrm{abB}$ & $59,3 \mathrm{cB}$ & 232,8 \\
Mistura formulada & $5337 \pm 423 \mathrm{aA}$ & $96,4 \mathrm{aA}$ & 13,3 & $3048 \pm 917 \mathrm{aB}$ & $71,6 \mathrm{aB}$ & 118,1 \\
Média & 3800 & 80,8 & - & 2825 & 62,2 & - \\
CV (\%) & 31,9 & 25,9 & - & 11,1 & 15,5 & - \\
\hline
\end{tabular}

* Médias seguidas das mesmas letras em maiúscula na linha correspondente à mesma variável avaliada entre época de aplicação, não diferem estatisticamente entre si em nível de $5 \%$ de probabilidade pelo teste de Tukey. ** Médias seguidas das mesmas letras em minúscula na coluna não diferem estatisticamente entre si em nível de $5 \%$ de probabilidade pelo teste de Tukey.

Ciência Rural, v.43, n.7, jul, 2013. 
Tabela 3 - Efeito da interação entre nível de resistência e época de aplicação sobre a produtividade (PR \pm IC), eficiência de controle (EF) e área abaixo da curva de progresso da doença (AACPD), Ponta Grossa, PR, 2008.

\begin{tabular}{|c|c|c|c|}
\hline \multirow[t]{2}{*}{ Variável } & \multirow[t]{2}{*}{ Época de aplicação } & & \\
\hline & & Resistente & Moderadamente suscetível \\
\hline \multirow{2}{*}{$\operatorname{PR}\left(\mathrm{kg} \mathrm{ha}^{-1}\right)$} & Preventivo & $4266 \pm 589 \mathrm{aA}$ & $3336 \pm 1530 \mathrm{aB}$ \\
\hline & Curativo & $3809^{1} \pm 279 \mathrm{bA}$ & $1841 \pm 418 \mathrm{bB}$ \\
\hline \multirow{2}{*}{$\begin{array}{l}\text { Média } \\
\text { CV (\%) }\end{array}$} & & 4037 & 2588 \\
\hline & & 7,9 & 40,8 \\
\hline \multirow{2}{*}{$\mathrm{EF}(\%)$} & Preventivo & $100 \mathrm{aA}$ & $61,6 \mathrm{aB}$ \\
\hline & Curativo & $100 \mathrm{aA}$ & $24,4 \mathrm{bB}$ \\
\hline \multirow{2}{*}{$\begin{array}{l}\text { Média } \\
\text { CV (\%) }\end{array}$} & & 100 & 43 \\
\hline & & - & 61 \\
\hline \multirow{2}{*}{ AACPD } & Preventivo & 0 & 233,8 \\
\hline & Curativo & 0 & 412.5 \\
\hline
\end{tabular}

* Médias seguidas das mesmas letras em maiúscula na linha não diferem estatisticamente entre si em nível de 5\% de probabilidade pelo teste de Tukey. ** Médias seguidas das mesmas letras em minúscula na coluna não diferem estatisticamente entre si em nível de $5 \%$ de probabilidade pelo teste de Tukey. ${ }^{1}$ Aplicação ausente(limiar de ação não atingido).

corroboram os reportados por REIS et al. (1996), que, em genótipos suscetíveis, a severidade pode atingir níveis elevados, comprometendo a produtividade de grãos; com decréscimos de produtividade variando no intervalo de $30 \%$ a $50 \%$.

Com aplicações preventivas (Tabela 3), foi possível atingir incrementos na produtividade, sendo que todos os ingredientes ativos utilizados responderam positivamente sobre esta variável nestas aplicações, como mostra a tabela 2.

Os dados deAACPD da tabela 3 mostram que houve ausência da evolução da epidemia de ferrugem na cultivar resistente e, como consequência, nenhuma aplicação curativa foi efetuada. De alguma maneira, três aplicações preventivas na cultivar resistente resultaram em 10,7\% de aumento na produtividade. Possivelmente, houve um efeito positivo da aplicação dos fungicidas sobre os processos fisiológicos das plantas de trigo, acarretando, assim, esse acréscimo de produtividade, embora trabalhos científicos necessitem ser elaborados para relatarem esses efeitos.

A cultivar moderadamente suscetível incrementou $44,8 \%$ na produtividade com três aplicações preventivas, em relação a duas aplicações curativas executadas (Tabela 3).

O retorno econômico (Tabela 5) para cultivar resistente com aplicação de tebuconazole + trifloxistrobina de forma preventiva apresentou valores

Tabela 4 - Efeito da interação entre ingredientes ativos e níveis de resistência sobre a produtividade (PR $\pm \mathrm{IC})$, eficiência de controle $(\mathrm{EF}) \mathrm{e}$ área abaixo da curva de progresso da doença (AACPD), Ponta Grossa, PR, 2008.

\begin{tabular}{|c|c|c|c|c|c|c|}
\hline \multirow{2}{*}{ Ingredientes ativos } & \multicolumn{3}{|c|}{ - } & \multicolumn{3}{|c|}{ 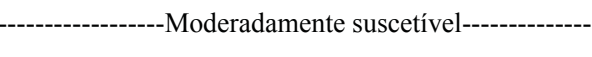 } \\
\hline & PR $\left(\mathrm{kg} \mathrm{ha}^{-1}\right)$ & $\mathrm{EF}(\%)$ & AACPD & PR $\left(\mathrm{kg} \mathrm{ha}^{-1}\right)$ & $\mathrm{EF}(\%)$ & AACPD \\
\hline Testemunha & $3423 \mathrm{bA}$ & $100,0 \mathrm{aA}$ & 0 & $1312 \mathrm{~dB}$ & $0,0 \mathrm{~dB}$ & 647,4 \\
\hline Tebuconazole & $3967 \pm 94 \mathrm{abA}$ & $100,0 \mathrm{aA}$ & 0 & $2842 \pm 1018 \mathrm{bB}$ & $58,3 \mathrm{bB}$ & 204,6 \\
\hline Trifloxistrobina & $4390 \pm 256 \mathrm{aA}$ & $100,0 \mathrm{aA}$ & 0 & $2184 \pm 1836 \mathrm{cB}$ & $45,8 \mathrm{cB}$ & 309,2 \\
\hline Mistura formulada & $4371 \pm 916 \mathrm{aA}$ & $100,0 \mathrm{aA}$ & 0 & $4015 \pm 917$ aA & $67,9 \mathrm{aB}$ & 131,4 \\
\hline Média & 4037 & 100 & - & 2588 & 30 & - \\
\hline CV (\%) & 11,2 & - & - & 43,9 & 69,9 & - \\
\hline
\end{tabular}

* Médias seguidas das mesmas letras em maiúscula na linha correspondente a mesma variável avaliada entre os níveis de resistência, não diferem estatisticamente entre si em nível de $5 \%$ de probabilidade pelo teste de Tukey. ** Médias seguidas das mesmas letras em minúscula na coluna não diferem estatisticamente entre si em nível de $5 \%$ de probabilidade pelo teste de Tukey.

Ciência Rural, v.43, n.7, jul, 2013. 
Tabela 5 - Receita bruta, custo de implantação e retorno econômico para controle da ferrugem da folha entre os tratamentos realizados, Ponta Grossa, PR, 2008.

\begin{tabular}{|c|c|c|c|c|}
\hline Ingredientes ativos & Época de aplicação & Receita Bruta $\left(\mathrm{R} \$\right.$ ha $\left.^{-1}\right)$ & Custo de implantação $\left(\mathrm{R} \$\right.$ ha $\left.^{-1}\right)$ & Retorno econômico $\left(\mathrm{R} \$\right.$ ha $\left.^{-1}\right)$ \\
\hline & \multicolumn{4}{|c|}{ 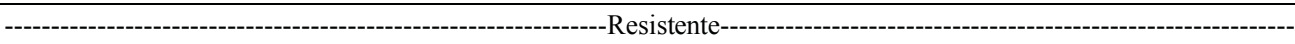 } \\
\hline Testemunha & - & 1677,12 & 1105,55 & 571,58 \\
\hline Tebuconazole & Preventiva & 1976,78 & 1281,8 & 694,98 \\
\hline Trifloxistrobina & Preventiva & 2241,51 & 1263,8 & 977,71 \\
\hline Mistura formulada & Preventiva & 2465,41 & 1336,58 & 1128,83 \\
\hline Tebuconazole & Curativa (aa) & 1910,56 & 1105,55 & 805,01 \\
\hline Trifloxistrobina & Curativa (aa) & 2060,8 & 1105,55 & 955,25 \\
\hline \multirow[t]{2}{*}{ Mistura formulada } & Curativa (aa) & 1817,66 & 1105,55 & 712,11 \\
\hline & & -------------Mod & adamente suscetível------------- & \\
\hline Testemunha & - & 642,97 & 1105,55 & $-462,57^{*}$ \\
\hline Tebuconazole & Preventiva & 1752,25 & 1281,8 & 470,45 \\
\hline Trifloxistrobina & Preventiva & 1377,69 & 1263,8 & 113,89 \\
\hline Mistura formulada & Preventiva & 2764,81 & 1336,58 & 1428,24 \\
\hline Tebuconazole & Curativa & 1032,46 & 1223,05 & $-190,59^{*}$ \\
\hline Trifloxistrobina & Curativa & 762,76 & 1211,05 & $-448,28^{*}$ \\
\hline Mistura formulada & Curativa & 1169,43 & 1259,57 & $-90,13 *$ \\
\hline
\end{tabular}

(aa) - aplicação ausente. * Saldos negativos enfatizam perdas do retorno econômico em função da baixa eficiência de controle dos fungicidas testados para a ferrugem da folha.

consideráveis em relação aos outros ingredientes ativos aplicados isoladamente. Entretanto, valores próximos a este foram observados mesmo quando as aplicações curativas permaneceram ausentes.

Ainda na tabela 5, para a cultivar moderadamente suscetível, maiores valores de retorno econômico foram atingidos em aplicações preventivas e a aplicação de tebuconazole + trifloxistrobina preventivamente foi a que proporcionou maior retorno econômico.

O presente trabalho é luz da especulação da relação entre eficiência de controle versus viabilidade econômica, e recomenda-se a repetição deste sob outras condições climáticas para estudos mais intensos.

\section{CONCLUSÃO}

Os resultados deste trabalho indicam que o emprego da resistência genética é um método eficiente e prático no controle de ferrugem da folha, e a não significância dos valores de eficiência entre as épocas de aplicação (preventiva e curativa) para a cultivar 'BRS 220' (resistente) implica o uso de limiares de ação, a fim de atingir um retorno econômico aceitável e consequentemente utilização racional dos fungicidas.

Para cultivar 'Vanguarda' (moderadamente suscetível), a utilização do controle químico é indispensável, dando-se preferência ao uso de mistura de ingredientes ativos (triazóis+estrobilurinas) em aplicações preventivas, a fim de aumentar a eficácia de controle e o retorno econômico. Aplicações curativas não foram eficientes no controle da ferrugem da folha na cultivar 'Vanguarda' e, em consequência desse fato, o retorno econômico apresentou saldos negativos.

\section{REFERÊNCIAS}

BARROS, B.C. et al. Resposta de cultivares de trigo (Triticum aestivum L.) ao controle químico das principais doenças fúngicas da cultura. Summa Phytopathologica, v.32, n.3 p.239-246, 2006. Disponível em: $<$ http://www.scielo.br/scielo.php?script=sci arttext\&pid $=$ S0100-54052006000300005\&lang=pt $>$. Acesso em: 20 jul. 2008. doi: 10.1590/S0100-54052006000300005.

BOHATCHUK, D.A. et al. Modelo de ponto crítico para estimar danos de doenças foliares do trigo em patossistema múltiplo. Tropical Plant Pathology, v.33, n.5, p.363-369, 2008. Disponível em: $\quad<\mathrm{http}: / /$ www.scielo.br/scielo.php?script=sci arttext\&pid $=\mathrm{S} 1982-56762008000500004 \&$ lang $=\mathrm{pt}>$. Acesso em: 15 maio 2008. doi: 10.1590/S1982-56762008000500004.

CAIERÃO, E. et al. Efeito de níveis de severidade e incidência da ferrugem-da-folha e ferrugem-do-colmo no rendimento de linhagens de aveia. Pesquisa Agropecuária Brasileira, v.36, n.1, p.43-52, 2001. Disponível em: <http:// www.scielo.br/scielo.php? script $=$ sci arttext\&pid $=$ S0100204X2001000100006\&lang=pt>. Acesso em: 10 maio 2008. doi: 10.1590/S0100-204X2001000100006.

CHAVES, M.S.; et al. Resistência quantitativa à ferrugem da folha em genótipos de aveia branca: II - avaliação de componentes de 
resistência. Fitopatologia Brasileira, v.29, n.2, p.197-200, 2004 Disponível em: $<$ http://www.scielo.br/scielo.php?script=sci arttext\&pid $=\mathrm{S} 0100-41582004000100008 \&$ lang $=\mathrm{pt}>$. Acesso em: 20 jul. 2008. doi: 10.1590/S0100-41582004000100008.

DALLAGNOL, L.J. et al. Influência das doenças foliares no rendimento de grãos na cultura do trigo. Uruguaiana, v.13, n.2, p.20-27, 2006.

FELICIO, J.C. et al. Resistência à ferrugem da folha e potencial produtivo em genótipos de trigo. Bragantia, v.67, n.4, p.855-863, 2008. Disponível em: $<$ http://www.scielo.br/scielo.php?script=sci arttext\&pid $=$ S0006-87052008000400007\&lang $=$ pt $>$. Acesso em: 20 jul. 2008. doi: 10.1590/S0006-87052008000400007.

LARGE, E.C. Growth stages in cereals. Plant Pathology, v.3, p.128-129, 1954

LIMACHE C.T. Exemplos de escalas diagramáticas de evolução de enfermidades. Anais eletrônicos, 2008. Disponível em: $<$ http:// www.buscagro.com/cgi-bin/search.cgi?query=frutales; $n h=1>$. Acesso em: 20 jun. 2008.

PICININI, E.C.; FERNANDES, J.M.C. Efeito do tratamento de sementes com fungicidas sobre o controle de doenças na parte aérea do trigo. Fitopatologia Brasileira, v.25, n.5; p.515-520, 2003. Disnponível em: $<$ http://www.scielo.br/scielo.php?script=sci arttext\&pid $=$ S0100-41582003000500008\&lang $=\mathrm{pt}>$. Acesso em: 20 jul. 2008. doi: 10.1590/S0100-41582003000500008.

REIS, E.M. et al. Grain losses caused by the infection of wheat heads by Gibberellazeaein southern Brazil, from 1984 to 1994. Summa Phytopathologica, v.22, p.134-137. 1996.

REIS, E.M.; CASA, R.T. Danos causados por fungos associados a sementes de cereais de inverno. Summa Phytopathologica, v.31, p.138-140, 2005.

SILVA, O.C et al. Esquema de controle para as principais doenças do trigo para a cultivar 'BRS 220'. 2008. Disponível em: <http://sid.fundacaoabc.org.br/trigo/grupos_controle/BRS\%20 208.pdf>. Acesso em: 20 jul. 2008. 